\title{
MARKETING POLITIK MULYADI PADA PEMILIHAN UMUM DPR-RI TAHUN 2019 DI PROVINSI SUMATERA BARAT
}

\author{
Bismo Ghifary \\ Jurusan Ilmu Politik, Fakultas Ilmu Sosial dan Ilmu Politik, Universitas Andalas \\ Email: bismogghifary@gmail.com
}

\begin{abstract}
Abstrak
Menjadi wakil rakyat tentunya ialah hak seluruh individu di dalam masyarakat yang mampu memenangkan suara masyarakat untuk memilihnya. Proses tersebut berkaitan dengan marketing politik, dimana individu berupaya dalam memasarkan produk politiknya agar diketahui oleh masyarakat. Menurut Adman Nursal proses marketing politik itu ada tiga tahapan, Push marketing (bertatap muka langsung dengan masyarakat dengan memasarkan produk politiknya), Pull marketing (menggunakan media elektronik dan cetak untuk memasarkan produk politiknya), dan Pass marketing (menggunakan orang ketiga dalam memasarkan produk politiknya seperti individu/kelompok yang berpengaruh). Kemudian faktor dari adanya perspektif Masyarakat Minangkabau dalam melihat seorang pemimpin dengan 3T menjadi hal yang juga berpengaruh terhadap keberhasilan Mulyadi yang dinilai memilikinya. Asumsi dari peneliti bahwa Mulyadi sebagai incumben mampu menggunakan marketing politik sehingga memperoleh suara tertinggi se-Sumatera Barat. Tujuan penelitian untuk menganalisis marketing politik dan dampak 3T terhadap kandidat dan pemilih yang dilakukan oleh Mulyadi dalam memperoleh suara terbanyak DPR-RI Tahun 2019. Penelitian ini menggunakan metode kualitatif dengan tipe deskriptif. Hasil penelitian ini menunjukkan bahwa Mulyadi memang berhasil dalam memasarkan produk politik nya melalui marketing politik yang dilakukan. Namun yang juga berpengaruh besar dalam kemenangan Mulyadi memperoleh suara tertinggi yaitu faktor (Takah,Tageh,Tokoh) yang muncul di kalangan Masyarakat Minangkabau sebagai standar pemimpin yang ideal.
\end{abstract}

\section{Kata Kunci: Marketing Politik; Perolehan Suara Tertinggi; Takah; Tageh; Tokoh}

\begin{abstract}
Becoming a people's representative is, of course, the right of all individuals in society who are able to win people's votes to elect them. This process is related to political marketing, where individuals try to market their political products so that they are known by the public. According to Adman Nursal, the political marketing process has three stages, Push marketing (face to face with the community by marketing its political products), Pull marketing (using electronic and print media to market its political products), and Pass marketing (using a third person to market its political products). such as influential individuals / groups) Then the factor from the perspective of the Minangkabau community in seeing a leader with $3 T$ becomes something that also influences the success of Mulyadi who is considered to have it. The assumption of the researchers is that Mulyadi as an incumbent is able to use political marketing so that he gets the highest votes in West Sumatra. The research objective was to analyze political marketing and the impact of $3 T$ on candidates and voters by Mulyadi in obtaining the most votes in the DPR-RI in 2019. This study used a qualitative method with a descriptive type. The results of this study indicate that Mulyadi is indeed successful in marketing his political products through his political marketing. However, what also greatly influenced Mulyadi's victory in obtaining the highest votes were the factors (Takah, Tageh, Tokoh) that emerged in the Minangkabau community as the standard of ideal leaders.
\end{abstract}

Keywords: Political Marketing; Higest Votes; Takah; Tageh; Tokoh 


\section{PENDAHULUAN}

Perjalanan demokrasi di Indonesia secara bertahap terus menunjukkan peningkatan yang signifikan. Terbukanya arus kebebasan sebagai fondasi dasar dari bangunan demokrasi terus merambah ke berbagai aspek. Sistem pemerintahan demokrasi adalah bentuk pemerintahan yang mana warga negara menggunakan hak yang sama tidak secara pribadi tetapi melalui para wakil yang duduk di lembaga perwakilan. ${ }^{1}$ Wakil tersebut juga merupakan warga Negara yang berhak untuk mencalonkan diri sebagai wakil bagi masyarakat yang lain. Hal ini tidak jauh dari tanggung jawab yang dimiliki oleh masyarakat untuk menjalankan roda pemerintahan tersebut. Maka dari itu partisipasi publik merupakan suatu keharusan yang ada dalam negara demokrasi.

Salah satu bentuk dari partisipasi masyarakat dan ciri dari negara demokrasi adalah dengan diadakannya pemilihan umum yang dilakukan secara periodik di Indonesia. Kebanyakan negara demokrasi, pemilihan umum dianggap lambang sekaligus tolak ukur, dari demokrasi itu. Hasil pemilihan umum yang diselenggarakan dalam suasana keterbukaan dengan kebebasan berpendapat dan kebebasan berserikat, dianggap mencerminkan dengan agak akurat partisipasi serta aspirasi masyarakat. Masyarakat bebas menentukan pilihannya sendiri yang menurutnya pantas dan layak untuk dijadikan pemimpin serta dapat mewakili aspirasinya. ${ }^{2}$

Disisi pelaksanaanya penyelenggaraan pemilu tentu menjadikan setiap calon pemipin berlomba-lomba dalam mengambil hati masyarakat. Tentunya hal itu bertujuan agar hak suara dari setiap masyarakat dapat diperoleh oleh pemimpin tersebut. Untuk mempengaruhi pilihan masyarakat calon pemimpin menggunakan berbagai cara, salah satunya yaitu kampanye yang mana ialah sebuah strategi dalam pemasaran politik (marketing politik) yang memang memiliki berbagai macam dan merupakan suatu jalan untuk memenangkan suatu kandidat atau suatu partai politik dalam kontestasi politik.

Marketing politik menurut Adman Nursal setidaknya memiliki strategi yang bisa menjawab yaitu Pendekatan push marketing, adanya stimulan atau rangsangan yang diberikan oleh pasangan calon kepada pemilih sehingga mendorong mereka pergi ke Tempat Pemungutan Suara (TPS) dan mencoblos. Kemudian pull marketing yaitu pembentukan image pasangan calon sehingga memiliki dampak terhadap pemilih yang diharapkan mampu membangkitkan sentimen pemilih. Dan yang ketiga yaitu pass marketing yaitu strategi yang menggunakan individu atau kelompok untuk mempengaruhi opini pemilih. ${ }^{3}$

Daerah Sumatera Barat memang merupakan daerah yang dihuni oleh penduduk yang cukup masif, tidak hanya dari segi jumlah juga dari beragamnya masyarakat yang

\footnotetext{
${ }^{1}$ Rafael Raga Margan, 2001, “Pengantar Sosiologi Politik”, Jakarta, Penerbit Rineka Cipta, hal.201 ${ }^{2}$ Miriam Budiarjo, Dasar-Dasar Ilmu Politik, (Jakarta, PT Gramedia Pustaka Utama: 2010), edisi revisi, cet ke 4, hal.461.

${ }^{3}$ Sutrisno, "Komparasi teori marketing politik 4P menurut Niffenegger dan 3P menurut Adman Nursal", JPPUMA: Jurnal ilmu pemerintahan dan sosial politik UMA, Vol 6(2) (2018): 106-111, DOI: 10.31289/jppuma.v6i2.1617.
} 
tinggal disana. Hal itu menjadikan daerah Sumatera Barat memang merupakan titik fokus dari para calon pemimpin untuk berlomba-lomba dalam memenangkan hati masyarakatnya. Mulai dari pemimpin daerah, hingga pemimpin pusat dan juga presiden ingin menitik fokuskan kepada masyarakat Sumatera Barat. Jika melihat dari kultur masyarakat, masyarakat Sumatera Barat lebih memilih pemimpin yang memiliki takah, tageh, dan tokoh. Tokoh dan takah adalah paduan kata yang populer di kalangan orang Minang dalam memilih pemimpin. Seorang pemimpin harus memiliki sifat ketokohan (tokoh), seperti halnya dengan pemahaman dalam bahasa Indonesia, sebagai sifat yang didukung oleh kemampuan SDM memadai, populer, memiliki elektabilitas, integritas. ${ }^{4}$ Warga Minang etnis mayoritas di Sumatera Barat, punya standar pemimpin yang disebut 3T tokoh, takah, dan tageh.

Menurut orang Minang, orang yang pantas menjadi pemimpin bukanlah sekadar tokoh yang elit dan memiliki kemampuan lebih dari masyarakat kebanyakan, tapi juga memiliki karisma (takah) dan gairah atau semangat (tageh).${ }^{5}$ Hal itu melekat dalam kultur asli Minangkabau yang mana memang Sumatera Barat didominasi oleh orang minang. Standar yang seperti itu menjadi tantangan bagi setiap calon pemimpin untuk bisa memenangkan hati masyarakat.

\section{Marketing Politik}

Marketing politik adalah serangkaian aktifitas terencana, strategis tapi juga taktis, berdimensi jangka panjang dan pendek, untuk menyebarkan makna politik kepada pemilih. ${ }^{6}$ Hal ini tentunya merupakan kunci dasar bagi pemimpin dalam memperoleh kepercayaan dari masyarakat.

Tiga teori yang akan digunakan dalam penelitian ini adalah push marketing, pull marketing, pass marketing. Berikut definisi dari ketiga model strategi tersebut:

a. Push Marketing, Push Marketing adalah penyampaian produk politik secara langsung kepada para pemilih. Produk politik tersebut berupa kandidat yang mencalonkan diri pada suatu pemilihan umum dan kandidat itu sendiri. Strategi push marketing dilakukan dengan kegiatan kampanye politik secara langsung seperti pertemuan akbar, pengajian ibu ibu, dan bakti social.

b. Pull Marketing, Pull Marketing adalah proses penyampaian produk politik dengan memanfaatkan media masa. Media masa dalam aktivitas pemasaran politik memegang peranan yang sangat penting dalam memperkenalkan dan mensosialisaikan kandidat kepada masyarakat luas. Selain itu melalui media masa kandidat dapat menyebarluaskan visi misi dan program mereka kepada calon pemilih. Strategi marketing politik ini dilakukan dengan kampanye politik menggunakan media cetak seperti surat kabar maupun media elektronik seperti tv dan radio.

\footnotetext{
${ }^{4}$ Nursyiwan Efendi, "Budaya Politik Khas Minangkabau Sebagai Alternatif Budaya Politik Indonesia”, Jurnal Jurusan Antropologi FISIP Unand, 2014.

${ }^{5}$ Dikutip dari BBC News Indonesia https://www.bbc.com/indonesia/indonesia-47974094

${ }^{6}$ Adman Nursal, 2004. Political Marketing, Gramedia, Jakarta. Hal 23.
} 
c. Pass Marketing, Pass Marketing merupakan kegiatan penyampaian produk politik kepada influencer dan grup atau pihak yang memiliki pengaruh di masyarakat. Berbagai pihak yang memiliki pengaruh dimasyarakat memiliki nilai strategis bagi kandiadat, sebab dengan adanya daya pengaruh, para tokoh tersebut dapat meneruskan pesan pesan politik yang disampaikan para kandidat kepada masyarakat atau komunitasnya.

Strategi pass marketing ini dilakukan dengan menjalin hubungan politik dengan para tokoh agama, tokoh masyarakat, dan tokoh pemuda. Dalam hal ini kandidat dapat membuat perjanjian atau kontrak politik dengan tokoh tersebut sebagai suatu ikatan yang kuat, agar ketika kandidat yang dipasarkan memperoleh kemenangan, maka para tokoh itu dapat menuntut janji-janji politik yang dituangkan dalam kontrak, untuk kepentingan masyarakat dimana para tokoh tersebut berdomisili. ${ }^{7}$

\section{METODE PENELITIAN}

Pada penelitian ini peneliti mengunakan pendekatan kualitatif dengan menggunakan tipe penelitian deskriptif. Menurut Bogdan dan Taylor penelitian kualitatif merupakan sebagai prosedur penelitian yang menghasilkan data deskriptif yang berupa kata-kata tertulis atau lisan dari orang-orang atau perilaku yang diamati. ${ }^{8}$ Sejalan dengan defenisi di atas, Kirk dan Miller mendefenisikan penelitian kualitatif sebagai tradisi tertentu dalam ilmu pengetahuan sosial yang secara fundamental bergantung dari pengamatan pada manusia baik dalam kawasannya maupun dalam peristilahannya. ${ }^{9}$ Penelitian deskriptif dimaksudkan untuk mengeksplorasi dan mengklarifikasi mengenai sesuatu fenomena atau kenyataan sosial. ${ }^{10}$

\section{HASIL DAN PEMBAHASAN}

Dalam pemaparan hasil temuan lapangan peneliti ingin memaparkan mengenai Marketing Politik yang di lakukan Mulyadi pada pemilihan umum DPR-RI Tahun 2019 di Sumatera Barat dan faktor apa saja yang menjadikan Mulyadi memperoleh suara tertinggi se-Sumatera Barat. Faktor lain yang menjadi fokus peneliti yaitu adanya istilah takah, tageh, dan tokoh yang muncul dari masyarakat sebagai standar pemimpin yang ideal.

\section{Marketing Politik Mulyadi}

Mulyadi pada pemilihan DPR-RI 2019 menggunakan konsep marketing politik dalam upayanya mengambil hati masyarakat dalam memilihnya. Tentu dengan sudah 2 periode berturut turut pada 2009 dan juga 2014 di DPR-RI menjadi modal bagi mulyadi yang berupaya maju kembali pada DPR-RI 2019. Bahkan mulyadi juga mendapat

\footnotetext{
${ }^{7}$ Adman Nursal, (2004), Political marketing: Strategi memenangkan pemilu sebuah pendekatan baru kampanye pemilihan DPR, DPD, Presiden. Gramedia Pustaka Utama, Hal. 296

${ }^{8}$ Lexy J. Moleong, Metode Penelitian Kualitatif, Bandung: PT. Remaja Rosdakarya, 2002, hal.4

${ }^{9}$ Ibid. Hal.4

${ }^{10}$ Faisal, Format-Format Penelitian Sosial,Jakarta:PT. Raja Grafindo Persada,2005,hal.20.
} 
perolehan suara tertinggi di 2014 dan juga di 2019, terbanyak di wilayah pemilihan SeSumatera Barat. Kondisi ini menunjukkan bahwa Mulyadi dan tim berhasil menjual namanya agar dikenal baik oleh seluruh elemen masyarakat di Sumatera Barat.

Dalam upaya penyampaian produk politik nya kepada masyarakat peneliti menggunakan teori Marketing Politik 3T dari Adman Nursal, yaitu Push, Pull, Pass.

\section{Push Marketing}

Push marketing merupakan kondisi dimana seorang kandidat berupaya memberikan produk politiknya secara langsung kepada masyarakat, agar masyarakat nantinya dapat meyakinkan hati dalam menentukan pilihannya. Pada tahap ini Mulyadi dan tim berusaha meyakinkan masyarakat dengan beberapa cara yang sekiranya tepat dalam merangkul pemilih. Hal itu menjadi pertanyaan peneliti dalam wawancara langsung dengan beberapa tim sukses dari mulyadi sendiri. dalam proses wawancara peneliti dengan tim sukses dari Mulyadi yang mengatakan bahwa:

"Pemilihan DPR-RI 2019 bapak itu hanya bergerak sesekali namun dengan strategi yang jitu, dimana bapak dan tim menggunakan upaya canvassing dengan beberapa orang canvasser di daerah dalam menyampaikan produk politik nya kepada orang yang masih ragu dalam memilih. Tentunya hal itu juga dilewati dengan berbagai survey yang dilakukan di tiap tiap daerah pemilihan. Produk politik yang dijual kemasyarakat tentunya terkait apa-apa saja rentetan hasil kerja bapak selama duduk dua periode di DPR dari tahun 2009 hingga sekarang. Jadi kami itu mempunyai catatan program aspirasi yang sudah di tampung dari masyarakat, dan direalisasikan oleh bapak selama menjabat, itu merupakan hal yang kami jual kepada masyarakat, jadi kami itu menjual hal nyata saja."11

\section{Pull Marketing}

Pull marketing merupakan keadaan dimana kandidat memanfaatkan media massa, yaitu media cetak dan juga media elektronik. Terkait hal itu peneliti mewawancarai tim sukses lapangan Mulyadi yaitu Joni Hendra

"Saya bekerja di lapangan itu membawa beberapa perlengkapan tempur, seperti spanduk, baliho, brosur, leaflet, stiker, dan baju kaos. Kemudian saya mencoba berkomunikasi langsung dengan beberapa orang teman di daerah tempat tinggal saya, yang sekiranya memang sebagai tokoh masyarakat di tempat tinggal saya dengan menempel stiker, memasang spanduk dan baliho dan juga membagikan beberapa brosur dan leaflet langsung kepada masyarakat. penempatan media ini dilakukan secara merata, namun di daerah yang sekiranya strategis, misal jalan-jalan raya kami menggunakan baliho yang cukup besar. hal itu juga di sambut baik di daerah tempat tinggal saya. Dan begitu juga untuk pembagian baju kaos."

\section{Pass Marketing}

Kondisi ini dimana calon kandidat memanfaatkan orang ketiga seperti tokoh masyarakat, influencer dan juga orang-orang yang sekiranya di dengar oleh masyarakat sebagai objek untuk menyebarkan produk politik nya ke masyarakat agar masyarakat dapat mengenal sekaligus memilih kandidat tersebut.

Wawancara dengan Yon (Anggota DPRD Kota Bukittinggi) sebagai tokoh masyarakat.

"Mulyadi memang dikenal disini karna kerja nyata beliau, jadi sekali kali beliau berkunjung ke daerah daerah beliau menyempatkan bersilaturrahmi ke rumah rumah masyarakat yang ada di sana. Rumah saya pernah menjadi saksi kedatangan Mulyadi dan masyarakat dalam jumlah banyak dalam acara silaturrahmi mulyadi tersebut. Dari

\footnotetext{
${ }^{11}$ Wawancara dengan Lasmawan, Ajudan Pribadi, bertempat di kantor tim sukses Mulyadi Bukittinggi pada tanggal 17 Maret 2020.
} 
antusias masyarakat menghadiri acara tersebut dapat kita nilai bahwa masyarakat itu senang dengan pak Mulyadi, apa lagi kerja nyata beliau selama ini sudah diketahui oleh masyarakat. Saya dan teman-teman mencoba mengundang melalui rumah-rumah yang ada di Guali Bancah ini. Dan Dalam pengumpulan massa alhamdulillah tidak terlalu sulit, karena dengan mendengar nama Mulyadi masyarakat di sini begitu antusias."

Penerapan konsep marketing politik 3P berpengaruh bagi kandidat dan juga masyarakat, Push marketing dimana kandidat menyampaikan produk politiknya melalui pendekatan persuasif, pertemuan akbar, atau pertemuan antara tokoh masyarakat yang nantinya masyarakat akan mengenal dan memahami tujuan politik dari kandidat tersebut.

Kemudian Pull Marketing yang merupakan cara pengenalan kandidat melalui media cetak atau elektronik seperti baliho,spanduk,stiker,leaflet dll, kehadiran media tersebut dampaknya bagi masyarakat mereka bisa mengenal dan mengingat kandidat tersebut melalui sebuah gambar. Hal ini yang nantinya dapat mempengaruhi psikologis dari masyarakat dalam menentukan pilihan pada saat pencoblosan.

Pass marketing juga merupakan cara dari kandidat mencoba menarik suara masyarakat melalui orang ketiga seperti tokoh masyarakat. Hubungan baik yang dijaga oleh kandidat menjadikan tokoh masyarakat yang biasanya didengar oleh masyarakatnya karena di segani menjadi memilihnya. Kondisi tersebut akan menjadikan keuntungan bagi kandidat karena telah memegang orang yang didengar di tengah masyarakat.

\section{Takah Tageh Tokoh sebagai faktor kemenangan Mulyadi}

Konsep ini sejatinya sudah ada lama di antara masyarakat Minangkabau, orang minang menilai pemimpin yang ideal itu dari Takah, yang merupakan wujudnya, kemudian Tageh yang merupakan gairahnya dalam memimpin, lalu Tokoh ketokohan beliau selama ini yang terbentuk di mata masyarakat. Hal ini peneliti kuatkan dengan hasil wawancara dengan inyiak Suwardi mengenai 3T, bertempat di Gulai Bancah

"Pemimpin itu menurut saya harus bisa menjadi contoh bagi masyarakat, bisa menjaga hubungan baik dengan masyarakat, dan juga peduli kepada masyarakat. Berbicara tentang Takah, takah itu kalau di Minangkabau artinya kharisma atau wujud dari orang tersebut, kemudian Tageh yang bisa di artikan sebagai gairah yang di maksudkan gairah atau semangat seorang pemimpin dalam memimpin, dan juga Tokoh pandangan masyarakat tentang beliau selama ini, memang beliau di sebut sebagai tokoh karna mampu menjaga kepercayaan dan mewujudkan aspirasi dari masyarakat. Beliau kalau menurut saya memang memiliki hal-hal ini yang menjadikan kunci bagi beliau untuk memenangkan suara masyarakat."

Dari pernyataan informan diatas peneliti mengambil kesimpulan bahwa faktor 3T merupakan hal yang begitu berpengaruh besar terhadap keterpilihan Mulyadi. Beliau memiliki penampilan layaknya seorang pemimpin beliau memiliki Takah, lalu beliau memiliki semangat dalam memimpin atau gairah dalam memimpin tageh, kemudian sosok beliau di masyarakat juga sudah terkenal dengan anggota DPR-RI yang di pandang oleh sebagian besar masyarakat Sumatera Barat.

Marketing politik yang digunakan oleh Mulyadi yaitu 3P, push marketing yang mana Mulyadi dan tim turun langsung bertatap muka dengan masyarakat dan menyampaikan produk politiknya. Proses ini selain menyampaikan produk politik dari Mulyadi yang menjadikannya dapat dipandang sebagai tokoh, juga membentuk image Mulyadi sendiri di mata masyarakat yang terkait dengan kharisma atau takah dari Mulyadi sebagai pemimpin. Proses ini seiring berjalannya marketing yang dilakukan oleh 
Mulyadi dan tim akan membentuk perspektif tersendiri yang muncul dari masyarakat tentang Mulyadi.

Takah, tageh, dan tokoh yang terkenal ketika pemilihan umum 2019 yang dikaitkan dengan pemilihan presiden menjadikan masyarakat minang memiliki standar baku seorang pemimpin untuk memimpin mereka. Ketika seorang pemimpin itu memiliki ketakahan (takah) beliau akan mampu dalam memimpin karena wujud nya saja wujud seorang pemimpin, kemudian tageh, gairah nya dalam melakukan sesuatu itu selalu bersemangat, lalu tokoh ketokohan seseorang dapat dilihat ketika beliau sudah melakukan suatu hal yang bisa berguna bagi masyarakat.

Jadi dalam temuan peneliti di lapangan tentang kemenangan Mulyadi itu tidak sebatas beliau melakukan Marketing politik saja. Namun pengaruh dari takah, tageh, tokoh yang merupakan persepsi masyarakat tentang seorang pemimpin yang ideal merupakan faktor tingginya suara Mulyadi. Selain beliau dan tim memang melakukan marketing yang sekiranya jitu, seperti strategi canvassing untuk memastikan suara masyarakat. Selain itu Mulyadi menjalin hubungan baik dengan tokoh-tokoh masyarakat, serta penggunaan baliho untuk kampanye, spanduk, leaflet, stiker dan media-media lain.

\section{KESIMPULAN}

Marketing politik sangat berpengaruh terhadap keterpilihan seorang calon dan juga terhadap masyarakat. Marketing politik memudahkan calon untuk menyampaikan produk politiknya kepada masyarakat, sedangkan bagi masyarakat dengan adanya program-program mereka juga bisa mengenal lebih baik calon yang akan memimpinnya sebelum nantinya akan menentukan pilihan. Serta kemenangan Mulyadi mendapat suara tertinggi tidak terlepas dari takah, tageh, dan tokoh yang dinilai oleh masyarakat. Kharisma, semangat, dan juga sosok tokoh yang selama ini dinilai mampu memimpin tersebut menjadikan masyarakat menyukai Mulyadi.

\section{DAFTAR PUSTAKA}

Efendi, Nursyiwan. 2014. "Budaya Politik Khas Minangkabau Sebagai Alternatif Budaya Politik Indonesia”, Jurnal Jurusan Antropologi FISIP Unand Nurfitriani, 2017. "Pemasaran Politik Bupati Bima Terpilih Pada Pilkada Kabupaten Bima Tahun 2015” dalam UMA : Jurnal Ilmu Pemerintahan, Volume 5 (2) Hal 71-78.

Firmanzah. 2008. Antara Pemahaman Dan Realitas ,Jakarta : Yayasan Obor Indonesia 2010. Persaingan, Legitimasi, Dan Marketing Politik, Jakarta :Yayasan Obor Indonesia

Lexy J. Moleong. 2004. Metode Penelitian Kualitatif, Bandung, PT.Remaja Rosdakarya. Miriam Budiardjo. 2008.Dasar-Dasar Ilmu Politik. Jakarta: PT Gramedia PustakaUtama. Newman, I Bruce. 1999.The mass Marketing of Politic, Democracy in Age of Manufactured of image,London, New Delhi 
Niadharma, Ajeng. 2016. "Strategi Pemasaran Politik Pasangan Sambari-Qosim Dalam Pemilihan Kepala Daerah Gresik 2015" Jurnal Politik Muda, Volume 5 No 3, Hal 369-374.

Nursal, Adman. 2004. Political Marketing: Strategi Memenangkan Pemilu Sebuah Pendekatan Baru Kampanye Pemilihan DPR, DPD, Presiden. Jakarta : PT Gramedia Pustaka Utama.

Robert K.Yin. 2008. Studi Kasus, Desain Dan Metode. Jakarta. PT. Raja Grafindo Persada.

Suherman, Ansar. 2017. "Strategi Marketing Politik Calon Independen Dalam Konstestasi Pilkada Serentak Tahun 2017 Di Kabupaten Buton Selatan” Jurnal Ilmu Sosial, Volume 16 No 1, Hal 9-19.

Sukandarrumidi, Haryanto. 2014. Dasar-Dasar Penulisan Proposal Penelitian. Gadjah MadaUniversity Press.

Sutrisno, 2018. "Komparasi Teori Marketing Politik 4P Menurut Niffenegger Dan $3 P$ Menurut Adman Nursal" dalam UMA : Jurnal Ilmu Pemerintahan Dan Sosial Politik Volume 6 (2) Hal 106-111.

Zamili, Moh. 2015. "Menghindar Dari Bias: Praktik Triangulasi Dan Kesahihan Riset Kualitatif" Jurnal Lisan Al-Hal, Volume 9 No 2 